Louisiana State University

LSU Digital Commons

Faculty Publications

Department of Biological Sciences

$5-1-2006$

\title{
Testing metabolic ecology theory for allometric scaling of tree size, growth and mortality in tropical forests
}

\author{
Helene C. Muller-Landau \\ University of Minnesota Twin Cities \\ Richard S. Condit \\ Apache Point Observatory \\ Jerome Chave \\ Universite Paul Sabatier Toulouse III \\ Sean C. Thomas \\ University of Toronto \\ Stephanie A. Bohlman \\ Princeton University
}

See next page for additional authors

Follow this and additional works at: https://digitalcommons.Isu.edu/biosci_pubs

\section{Recommended Citation}

Muller-Landau, H., Condit, R., Chave, J., Thomas, S., Bohlman, S., Bunyavejchewin, S., Davies, S., Foster, R., Gunatilleke, S., Gunatilleke, N., Harms, K., Hart, T., Hubbell, S., Itoh, A., Kassim, A., LaFrankie, J., Lee, H., Losos, E., Makana, J., Ohkubo, T., Sukumar, R., Sun, I., Nur Supardi, M., Tan, S., Thompson, J., Valencia, R., Muñoz, G., Wills, C., Yamakura, T., Chuyong, G., Dattaraja, H., Esufali, S., \& Hall, P. (2006). Testing metabolic ecology theory for allometric scaling of tree size, growth and mortality in tropical forests. Ecology Letters, 9 (5), 575-588. https://doi.org/10.1111/j.1461-0248.2006.00904.x

This Article is brought to you for free and open access by the Department of Biological Sciences at LSU Digital Commons. It has been accepted for inclusion in Faculty Publications by an authorized administrator of LSU Digital Commons. For more information, please contact ir@lsu.edu. 


\section{Authors}

Helene C. Muller-Landau, Richard S. Condit, Jerome Chave, Sean C. Thomas, Stephanie A. Bohlman, Sarayudh Bunyavejchewin, Stuart Davies, Robin Foster, Savitri Gunatilleke, Nimal Gunatilleke, Kyle E. Harms, Terese Hart, Stephen P. Hubbell, Akira Itoh, Abd Rahman Kassim, James V. LaFrankie, Hua Seng Lee, Elizabeth Losos, Jean Remy Makana, Tatsuhiro Ohkubo, Raman Sukumar, I. Fang Sun, M. N. Nur Supardi, Sylvester Tan, Jill Thompson, Renato Valencia, Gorky Villa Muñoz, Christopher Wills, Takuo Yamakura, George Chuyong, Handanakere Shivaramaiah Dattaraja, Shameema Esufali, and Pamela Hall 


\section{LETTER}

\section{Testing metabolic ecology theory for allometric scaling of tree size, growth and mortality in tropical forests}

Helene C. Muller-Landau, ${ }^{1 *}$ Richard S. Condit, ${ }^{2}$ Jerome Chave, ${ }^{3}$ Sean C. Thomas, ${ }^{4}$ Stephanie A. Bohlman, ${ }^{5}$ Sarayudh Bunyavejchewin, ${ }^{6}$ Stuart Davies, ${ }^{2}$ Robin Foster, ${ }^{7}$ Savitri Gunatilleke, ${ }^{8}$ Nimal Gunatilleke, ${ }^{8}$ Kyle E. Harms, ${ }^{2,9}$ Terese Hart, ${ }^{10}$ Stephen P. Hubbell, ${ }^{2,11}$ Akira Itoh, ${ }^{12}$ Abd Rahman Kassim, ${ }^{13}$ James V. LaFrankie, ${ }^{14}$, Hua Seng Lee, ${ }^{15}$ Elizabeth Losos, ${ }^{16}$ JeanRemy Makana, ${ }^{17}$ Tatsuhiro Ohkubo, ${ }^{18}$ Raman Sukumar, ${ }^{19}$ I-Fang Sun, ${ }^{20}$ Nur Supardi M. N., ${ }^{21}$ Sylvester Tan, ${ }^{22}$ Jill Thompson, ${ }^{23}$ Renato Valencia, ${ }^{24}$ Gorky Villa Muñoz, ${ }^{24}$ Christopher Wills, ${ }^{25}$ Takuo Yamakura, ${ }^{26}$ George Chuyong, ${ }^{27}$ Handanakere Shivaramaiah Dattaraja, ${ }^{19}$ Shameema Esufali, ${ }^{8}$ Pamela Hall, ${ }^{2,28}$ Consuelo Hernandez, ${ }^{24}$ David Kenfack, ${ }^{29}$ Somboon Kiratiprayoon, ${ }^{30}$ Hebbalalu S. Suresh, ${ }^{19}$ Duncan Thomas, ${ }^{31}$ Martha Isabel Vallejo ${ }^{32}$ and Peter Ashton $^{33}$

\begin{abstract}
The theory of metabolic ecology predicts specific relationships among tree stem diameter, biomass, height, growth and mortality. As demographic rates are important to estimates of carbon fluxes in forests, this theory might offer important insights into the global carbon budget, and deserves careful assessment. We assembled data from 10 oldgrowth tropical forests encompassing censuses of 367 ha and $>1.7$ million trees to test the theory's predictions. We also developed a set of alternative predictions that retained some assumptions of metabolic ecology while also considering how availability of a key limiting resource, light, changes with tree size. Our results show that there are no universal scaling relationships of growth or mortality with size among trees in tropical forests. Observed patterns were consistent with our alternative model in the one site where we had the data necessary to evaluate it, and were inconsistent with the predictions of metabolic ecology in all forests.
\end{abstract}

\section{Keywords}

Asymmetric competition, demographic rates, forest dynamics, light availability, metabolic theory of ecology, resource competition theory, tree allometry.

\footnotetext{
${ }^{1}$ Department of Ecology, Evolution and Behavior, University of Minnesota, 1987 Upper Buford Circle, St Paul, MN 55108, USA ${ }^{2}$ Smithsonian Tropical Research Institute, Unit 0948, APO-AA, 34002-0948, USA

${ }^{3}$ Laboratoire Evolution et Diversité Biologique UMR 5174, CNRSIUPS, bâtiment IVR3, Université Paul Sabatier, 118 route de Narbonne, 31062 Toulouse, France

${ }^{4}$ Faculty of Forestry, University of Toronto, 33 Willcocks St, Toronto, ON, Canada

${ }^{5}$ Department of Ecology and Evolutionary Biology, Princeton University, Princeton, NJ, USA
}

\footnotetext{
${ }^{6}$ Research Office, National Parks Wildlife and Plant Conservation Department, 61 Paholyothin Road, Chatuchak, Bangkok 10900, Thailand

${ }^{7}$ The Field Museum, 1400 S. Lake Shore Drive, Chicago, IL 60605-2496, USA

${ }^{8}$ Department of Botany, Faculty of Science, University of Peradeniya, Peradeniya 20400, Sri Lanka

${ }^{9}$ Department of Biological Sciences, Louisiana State University, 202 Life Sciences Building, Baton Rouge, LA 70803-1715, USA

${ }^{10}$ Wildlife Conservation Society, International Programs, 185th St. and Southern Blvd, Bronx, NY 10460, USA
} 
${ }^{11}$ Department of Plant Biology, University of Georgia, Athens, GA 30604, USA

${ }^{12}$ Laboratory of Plant Ecology, Graduate School of Science, Osaka City University, Osaka 558-8585, Japan

${ }^{13}$ Forest Management and Ecology Program, Forestry and Conservation Division, Forest Research Institute Malaysia, 52109 Kepong, Selangor, Malaysia

${ }^{14}$ Center for Tropical Forest Science-Arnold Arboretum Asia Program, Nanyang Technological University, 1 Nanyang Walk, Singapore 637617, Singapore

${ }^{15}$ Sarawak Forest Department, Jalan Stadium, Petra Jaya, Kuching, Sarawak 93660, Malaysia

${ }^{16}$ Organization for Tropical Studies, Duke University, Durham, NC, USA

${ }^{17}$ Wildlife Conservation Society - DR Congo Program, 257 Sherbourne Street, Apt no. 115, Toronto, ON, Canada M5A 3 Y9

${ }^{18}$ Department of Forest Science, Utsunomiya University, 350

Minemachi, Utsunomiya 321-8505, Japan

${ }^{19}$ Center for Ecological Science, Indian Institute of Science, Bangalore 560012, India

${ }^{20}$ Center for Tropical Ecology and Biodiversity, Tunghai University, Taichung, ROC 40704, Taiwan

${ }^{21}$ Forest Ecology Unit, Forestry and Conservation Division, Forest Research Institute Malaysia, Kepong, 52109 Kuala Lumpur, Malaysia

${ }^{22}$ Forest Research Center, KM 10 Jalan Datuk Amar Kalong Ningkan, 93250 Kuching, Sarawak, E., Malaysia

\section{INTRODUCTION}

Tree growth and mortality rates vary widely among tropical forests worldwide (Baker et al. 2003; Phillips et al. 2004), yet relationships of tree growth and mortality rates to tree diameter show fundamental similarities that suggest general underlying principles (Coomes et al. 2003). Recently, the theory of metabolic ecology has generated specific predictions about the functional form of these relationships (Enquist et al. 1999; Brown et al. 2004). Such a general theory could potentially advance fundamental understanding of forest structure and dynamics, and also provide a basis for predicting future changes in associated carbon pools and fluxes (Phillips et al. 1998; Clark et al. 2001).

The metabolic theory of ecology strives to apply basic principles of physics, chemistry and biology to explain the physiology and performance of individual organisms and thereby the structure of populations, communities and ecosystems (West et al. 1997; Brown et al. 2004). West et al. (1997) pioneered these efforts with predictions for the scaling of metabolic rates (in plants, gross photosynthetic rates) with body mass based on the scaling of resource uptake and redistribution within optimized networks (e.g. arteries and xylem). West et al. (1999) derived additional predictions for
${ }^{23}$ Institute for Tropical Ecosystem Studies, University of Puerto Rico Río Piedras, Box 21910, San Juan, PR 00931-1910, USA

${ }^{24}$ Herbario QCA. Department de Ciencias Biológicas, Pontificia Universidad Católica del Ecuador, Aptado 17-01-2184, Quito, Ecuador

${ }^{25}$ Division of Biological Sciences, University of California, San Diego, La Jolla, CA 92093-0116, USA

${ }^{26}$ Department of Biology, Faculty of Science, Osaka City University, Sugimoto, Sumiyoshi-ku, Osaka 558-8585, Japan

${ }^{27}$ Department of Life Sciences, University of Buea, PO Box 63 Buea, Cameroon

${ }^{28}$ Department of Biological Sciences, Florida State University, Tallahassee, FL 32306-4370, USA

${ }^{29}$ International Center for Tropical Ecology, University of Missouri Saint Louis, 8001 Natural Bridge Ave., St Louis, MO 63121, USA

${ }^{30}$ Department of Environmental Science, Faculty of Science and Technology, Thammasat University (Rangsit), Patumtani, Thailand

${ }^{31}$ Department of Forest Science, Oregon State University, 529 NW 31st Street, Corvallis, OR 97330, USA

${ }^{32}$ Instituto Alexander von Humboldt, Ministerio del Medio Ambiente, Calle 37 8-40 Mezzanine, Bogota, Colombia ${ }^{33}$ Center for Tropical Forest Science-Arnold Arboretum Asia Program, 22 Divinity Avenue, Cambridge, MA 02138, USA

*Correspondence: E-mail: hmuller@umn.edu

the scaling of height, biomass, diameter and leaf area in plants. In combination with assumptions relating growth and mortality to metabolic rate, Enquist et al. (1999) and Brown et al. (2004) extend these to make further predictions for the scaling of plant growth and mortality respectively.

There is considerable debate about the validity and consistency of the underlying assumptions of metabolic ecology (e.g. Dodds et al. 2001; Kozlowski \& Konarzewski 2004; Meinzer et al. 2005). For trees in particular, we suggest that the scaling of metabolic rates with size will depend not only on the potential for resource uptake and redistribution that is central to metabolic ecology theory, but also on availability of these resources. Small plants in the shaded understory of forests are much farther from their maximum potential metabolic rates than the canopy trees that overtop them. Light is a limiting resource for plant growth in tropical forests (Chazdon \& Pearcy 1986; King 1994; Graham et al. 2003), and competition for light is strongly size asymmetric (Weiner 1990). In addition, site-specific mortality factors might affect some size classes more than others and thus change the scaling of mortality with size. For example, hurricanes induce more mortality among large trees (Zimmerman et al. 1994), while fires and large mammals cause more mortality among small trees (Ickes et al. 2005; 
Sukumar et al. 2005). The scaling of growth with size is also expected to vary ontogenetically because of changes in relative expenditure on maintenance and reproduction (Kooijman 2000), as considered in some theoretical work on metabolic ecology (West et al. 2001).

Large-scale empirical patterns appear broadly consistent with the predictions of metabolic ecology theory (Brown et al. 2004), although substantial deviations have been found, especially (but not exclusively) when patterns are examined over smaller ranges of body size within particular taxonomic groups or ecosystems (Tilman et al. 2004). The predictions for the scaling of leaf mass with stem diameter and total plant biomass have both been supported (Niklas \& Enquist 2001; Enquist \& Niklas 2002), while the prediction for plant height with biomass has not (Niklas \& Enquist 2001). There appears to be considerable variability in the scaling of plant biomass with stem diameter (Li et al. 2005), with average scaling values inconsistent with theoretical predictions (Enquist et al. 1998). Nonetheless, both Niklas \& Enquist (2001) and Ernest et al. (2003) found that biomass growth (or production) scaled with biomass as predicted. Further, Enquist et al. (1999) were unable to reject the predicted scaling of tree diameter growth with diameter in their species-specific analyses for 40 of 45 species, although the power of their analyses was severely limited by sample size (for three of four species for which there were data on more than 100 individuals, the predictions were rejected). To our knowledge, no studies have yet tested the relatively new prediction for the scaling of mortality rates in plants (Brown et al. 2004). Given its potential to expand our understanding of plant communities, metabolic ecology theory merits thorough investigation of all its predictions.

Here we first summarize the predictions of metabolic ecology for the scaling of plant diameter, height, biomass, growth and mortality rates and the logic underlying and linking these predictions. We then examine how the predictions for growth and mortality change if we incorporate the scaling of resource availability as well as resource uptake ability with tree size, and if we use empirically observed allometric relationships rather than theoretically predicted ones as starting points. We use data on light availability and on tree diameter, height and biomass to test metabolic ecology predictions for tree allometry in one tropical forest and to parameterize the alternative, empirically based model. We evaluate both sets of predictions for growth and mortality using data for over 1.7 million trees in 10 tropical forests around the world.

\section{PREDICTIONS FROM METABOLIC ECOLOGY THEORY}

The foundations of metabolic ecology theory for plants, as detailed in West et al. (1997, 1999), are as follows:
M1 - Assumption: A plant's gross photosynthetic rate (its metabolic rate) is determined by its potential rates of resource uptake across its surface and resource redistribution through its body.

M2 - Assumption: The branching networks distributing resources through plants have a self-similar, fractal structure, a fixed smallest branch size, and are organized to minimize the energy required to distribute resources.

Implicit in M1 is the following assumption:

M3 - Implicit Assumption: A plant's access to resources does not limit its gross photosynthetic rate, or else scales with plant size in the same way potential rates of resource uptake and redistribution scale with plant size.

West et al. (1997, 1999) and Enquist \& Niklas (2002) use these assumptions to derive predictions for the scaling of biomass, stem diameter, photosynthetic rates, height and leaf allocation:

$M 4$ - Prediction: A plant's trunk diameter, $D$ scales with its biomass, $M$ as $M^{3 / 8}$ (thus $M \propto D^{8 / 3}$ ).

M5 - Prediction: A plant's height, $H$ scales with its biomass as $M^{1 / 4}$ and thus with $D^{2 / 3}$.

M6 - Prediction: A plant's leaf number and leaf mass, $L$ scale with $M^{3 / 4}$, and thus with $D^{2}$.

M7-Prediction: A plant's gross photosynthetic rate scales with $M^{3 / 4}$, and thus with $D^{2}$ and $L$.

Enquist et al. (1999) further assume

M8 - Assumption: A plant's biomass growth rate is proportional to its gross photosynthetic rate (its metabolic rate).

This allows growth to be related to biomass and diameter:

M9 - Prediction: A plant's biomass growth rate scales with $M^{3 / 4}$, and its diameter growth rate with $D^{1 / 3}$ (based on M4, M7 and M8).

Brown et al. (2004) make an analogous assumption for mortality:

M10 - Assumption: An individual's mortality rate is proportional to its mass-specific metabolic rate (its metabolic rate divided by its mass).

This leads to a prediction for the scaling of mortality with biomass, which we extend to a prediction for scaling with diameter:

M11 - Prediction: An individual's mortality rate scales with $M^{-1 / 4}$ and thus with $D^{-2 / 3}$ (based on M4, M7 and M10).

The assumptions about the scaling of growth and mortality with photosynthesis result in a further prediction for the 
relationship between the growth and mortality exponents (though never to our knowledge stated in previous papers):

M12 - Prediction: The difference between the scaling exponent for diameter growth with diameter and the scaling exponent for mortality with diameter is 1 (based on M8 and M10).

Note that this prediction does not rely upon the specific photosynthesis scaling assumption (M7).

\section{ALTERNATIVE PREDICTIONS INCORPORATING RESOURCE COMPETITION}

Consider the alternative foundation:

A1 - Assumption: A plant's gross photosynthetic rate is determined by both its access to resources and its potential rate of resource uptake.

A2 - Assumption: The most important resource for determining the scaling of photosynthetic rates with size among trees within forests is light; a forest tree's gross photosynthetic rate is proportional to its crown area times the light reaching its crown.

Instead of deriving the relationships of tree size with crown area and light from first principles, we use empirically observed relationships. Thus, our alternative is necessarily less general than pure metabolic ecology theory. For consistency with metabolic ecology theory, we represent the scaling of stem diameter, tree height, crown area, biomass, and resource availability as power functions, but with empirically fitted exponents $S_{\mathrm{L}}, S_{\mathrm{M}}, S_{\mathrm{H}}, S_{\mathrm{C}}$ :

A3 - Assumption: Within a forest, a tree's light availability scales with its height, $H$ as $H^{\mathcal{L}_{\mathrm{L}}}$.

A4 - Assumption: A tree's biomass scales with $D^{S_{\mathrm{M}}}$.

A5 - Assumption: A tree's height scales with $D^{S_{\mathrm{H}}}$.

A6 - Assumption: A tree's crown area scales with $D^{S_{C}}$.

The combination of these assumptions leads to a powerfunction prediction for photosynthesis:

A7 - Prediction: A tree's gross photosynthetic rate scales with $D^{S_{\mathrm{C}}+S_{\mathrm{H}} S_{\mathrm{L}}}$ (based on A2-A6).

Because they incorporate power functions, these assumptions and predictions (A3-A7) are equivalent to the predictions of metabolic ecology (M3-M7) if we think of crown area as equivalent to leaf mass or leaf area, and if the predictions of metabolic ecology prove correct such that $S_{\mathrm{L}}=0, S_{\mathrm{M}}=8 / 3, S_{\mathrm{H}}=2 / 3$ and $S_{\mathrm{C}}=2$.

In practice, we expect to see a shift in the relationship between light availability and height when trees grow out of the understory (where there is a strong vertical gradient in light availability) into the canopy (where all trees have some access to full sun). We expect a parallel shift in the relationships of height and biomass with diameter as height asymptotes in canopy individuals. We also expect the allometric and resource scaling exponents to vary among sites with soil, climate, tree species composition, and other factors, resulting in parallel variation in the scaling of photosynthetic rates.

If we retain the metabolic ecology assumption that biomass growth is proportional to gross photosynthesis $(\mathrm{A} 8=\mathrm{M} 8)$, then our prediction for the scaling of photosynthesis translates into predictions for the scaling of growth:

A9 - Prediction: A tree's biomass growth rate scales with $D^{S_{\mathrm{C}}+S_{\mathrm{H}} S_{\mathrm{L}}}$ and its diameter growth rate scales with $D^{S_{\mathrm{C}}+S_{\mathrm{H}} S_{\mathrm{L}}-S_{\mathrm{M}}+1}$ (based on $\mathrm{A} 4, \mathrm{~A} 7$ and A8, because

$$
\left.\frac{\mathrm{d} D}{\mathrm{~d} t}=\frac{\mathrm{d} M / \mathrm{d} t}{\mathrm{~d} M / \mathrm{d} D} \propto \frac{D^{S_{\mathrm{C}}+S_{\mathrm{H}} S_{\mathrm{L}}}}{D^{S_{\mathrm{M}}-1}}=D^{S_{\mathrm{C}}+S_{\mathrm{H}} S_{\mathrm{L}}-S_{\mathrm{M}}+1}\right) .
$$

Similarly, if we retain the metabolic ecology assumption that mortality is proportional to the mass-specific metabolic rate $(\mathrm{A} 10=\mathrm{M} 10)$, we arrive at a prediction for mortality.

A11-Prediction: A tree's mortality rate scales with $D^{S_{\mathrm{C}}+S_{\mathrm{H}} S_{\mathrm{L}}-S_{\mathrm{M}}}(\mathrm{A} 7$ and $\mathrm{A} 10)$.

As before, no matter what the precise scaling of photosynthetic rates with size (A7), A8 and A10 lead to A12 $=$ M12, a constant relationship between growth and mortality scaling exponents.

We expect considerable deviations from the hypothesized relationship of photosynthesis and mortality (A10) and thus between mortality and size (A11) because mortality depends not only on vulnerability (which is encapsulated in these resource-based predictions), but also on risks, which are likely to scale unpredictably. We also expect size-dependent changes in relative allocation to maintenance, defence, growth and reproduction to cause further deviations in the scaling of both mortality and growth with photosynthesis and size (A8-A12). Nonetheless, comparison with empirical data will allow us to see whether changes to assumptions about the scaling of photosynthetic rates (A1-A7) to incorporate resource availability lead to improvements in the predictions of the scaling of tree growth and mortality rates (A9 and A11) over the predictions of pure metabolic ecology (M9 and M11). We note that our alternative is conceptually similar to previous efforts, mostly in agriculture and forestry, that have predicted biomass accumulation as the product of light interception and light use efficiency (Kirschbaum et al. 1994; Sands 1996; Waring \& Running 1998).

Here we fit the power-function relationships assumed in A3-A6 to data on light availability below the canopy and on tree allometry for small (below canopy) and large (canopy) 
individuals for the one site in which we have appropriate data - Barro Colorado, Panama. We then use the resulting fitted parameters to predict the corresponding scaling exponents for diameter growth (A9) and mortality (A11) for below-canopy individuals at this site.

\section{MATERIALS AND METHODS}

\section{Study sites and data sets}

Our study sites are 10 large plots (25-52 ha each) in oldgrowth tropical forests around the world (see Table 1 and Losos \& Leigh 2004). All plots were censused two or more times at c. 5-year intervals using the standard methods of the Center for Tropical Forest Science (Condit 1998): all freestanding woody plants with a stem diameter $\geq 1 \mathrm{~cm}$ (at $1.3 \mathrm{~m}$ above the ground) were mapped, tagged, identified to species, and measured in diameter (with a precision of $0.1 \mathrm{~cm}$ - we excluded early censuses in which small stems were measured only to the nearest $0.5 \mathrm{~cm}$ ). We examined growth and mortality over one census interval (two censuses) at seven sites, and over two successive census intervals (three censuses) at three sites. We excluded data for individuals whose diameters were recorded as $1.0 \mathrm{~cm}$ to avoid inconsistencies in the definitions of this smallest size classes. (In some cases, any stem between 0.95 and $1.05 \mathrm{~cm}$ was recorded as a $1.0-\mathrm{cm}$ stem, while in others only stems between 1.00 and $1.05 \mathrm{~cm}$ were thus recorded.)

Data on light availability and on diameter, height and crown area allometries were collected at one of these sites, Barro Colorado, Panama. Biomass-diameter data were from a pantropical compilation (Chave et al. 2005).

\section{Light availability and tree size allometry}

Canopy openness was measured in Barro Colorado on a 5-m grid over 50 ha (Hubbell et al. 1999). At each point, a technician assessed the presence or absence of vegetation in the following height intervals: $2-5,5-10$, $10-20,20-30$ and $>30 \mathrm{~m}$. The canopy openness at the bottom of each height interval was then calculated as the fraction of sampled locations that have no vegetation above that height. Our measure of light availability at a given height is thus the probability that a point at that height is not shaded by vegetation directly above. A linear regression of log-transformed data was performed in each year to obtain power functions relating canopy openness to height, and parameters were averaged across years. CIs were obtained from 1000 bootstraps, which were carried out across $50 \times 50-\mathrm{m}$ subplots due to spatial autocorrelation.

Tree heights were measured on 9042 individuals of 223 woody dicot species in the Barro Colorado Nature Monument (Bohlman \& O'Brien 2006 and S.J. Wright, H.C. Muller-Landau, P. Spiro, S.C. Thomas, R. Condit, unpublished data). Eight crown radii per tree were measured for 849 individuals of 78 species at the same site, and crown area was calculated as pi times the square of the mean radius (Bohlman \& O'Brien 2006). For both tree heights and crown area, systematic correction factors were applied to account for measurement differences among investigators and normalize all measurements to the most accurate methods used: laser rangefinder measurements (Bohlman \& O'Brien 2006). Individual tree above-ground biomass and diameter data for 1504 individuals from moist tropical

Table 1 The 10 tropical forest dynamics plots used in this study and their site characteristics

\begin{tabular}{|c|c|c|c|c|c|c|}
\hline Site & $\begin{array}{l}\text { Plot } \\
\text { area (ha) }\end{array}$ & $\begin{array}{l}\text { Elevation } \\
\text { (m a.s.l.) }\end{array}$ & $\begin{array}{l}\text { Rainfall } \\
(\mathrm{mm})\end{array}$ & $\begin{array}{l}\text { Dry season } \\
\text { (months) }\end{array}$ & $T_{\max }\left({ }^{\circ} \mathrm{C}\right)$ & $T_{\min }\left({ }^{\circ} \mathrm{C}\right)$ \\
\hline Sinharaja Wilderness Area, Sri Lanka & 25 & 500 & 5016 & 0 & 24.7 & 20.4 \\
\hline La Planada Nature Reserve, Colombia & 25 & 1845 & 4415 & 0 & 23.8 & 12.9 \\
\hline Yasuni National Park, Ecuador & 25 & 230 & 3081 & 0 & 30.9 & 21.0 \\
\hline Lambir Hills National Park, Sarawak, Malaysia & 52 & 175 & 2664 & 0 & 30.3 & 22.9 \\
\hline Pasoh Forest Reserve, Malaysia & 50 & 80 & 1788 & 1 & 33.2 & 22.7 \\
\hline Barro Colorado Nature Monument, Panama & 50 & 140 & 2551 & 3 & 31.1 & 23.2 \\
\hline Edoro study area, Ituri Forest, Congo & $20 *$ & 775 & 1785 & 3 & 25.5 & 17.9 \\
\hline Lenda study area, Ituri Forest, Congo & $20 *$ & 775 & 1674 & 4 & 27.8 & 18.3 \\
\hline Huai Kha Khaeng Wildlife Sanctuary, Thailand & 50 & 595 & 1476 & 6 & 30.4 & 17.7 \\
\hline Mudumalai Wildlife Sanctuary, India & 50 & 1050 & 1250 & 4 & 28.2 & 17.3 \\
\hline
\end{tabular}

Rainfall is the average annual total; dry season length is the number of calendar months with average rainfall $<100 \mathrm{~mm}$. $T_{\max }$ and $T_{\min }$ are the average daily maximum and minimum temperatures respectively. Climate data for Yasuni are from S.J. Wright (personal communication); all other data are from Losos \& Leigh (2004). Plots are ordered by increasing dryness.

*The two Congo sites each consist of two 10-ha plots (the Edoro study area consists mainly of mixed forest, and the Lenda study area mainly of monodominant forest); all other sites are one contiguous rectangle or square. 
forests were from a pan-tropical compilation (Chave et al. 2005). Power functions relating tree height, crown area and biomass to stem diameter were fit using ordinary leastsquared regression on log-transformed data. Separate fits were carried out for individuals $<20-\mathrm{cm}$ diameter only (henceforth small individuals), and individuals $\geq 20 \mathrm{~cm}$ in diameter only (large individuals), and all individuals combined.

To obtain CI for the predictions of the growth and mortality exponents based on allometric and resource scaling exponents (A9 and A11), we bootstrapped 1000 times over the error distributions of the allometric and resource scaling exponents that went into the calculation.

\section{Growth}

To investigate the scaling of growth with size within each site, we first calculated mean absolute diameter growth rates $\left(\mathrm{cm}\right.$ year $^{-1}$ ) and mean initial diameters for each diameter class, with classes chosen to be approximately evenly distributed on a $\log$ (diameter) scale (see Appendix S1). Subsequent analyses were based on mean diameter growth rates within size classes rather than growth rates of individual trees to avoid undue influence of the many small individuals. In calculating mean growth rates within each size class, we excluded individuals whose stems were measured at different heights in the two censuses (due to changes in the height of buttresses).

We estimated the power function relating diameter growth rate, $g(D)$, and diameter,

$g(D)=\frac{\mathrm{d} D}{\mathrm{~d} t}=r D^{c}$

that was most consistent with the change in mean diameter growth rates among size classes. Because growth is a function of size and size changes continuously as growth occurs, a power-function relationship for continuous growth rate (eqn 1) implies that the expected diameter at time $t$ of an individual with initial diameter $D_{0}$ is

$D_{t}=\left[D_{0}^{1-c}+r(1-c) t\right]^{1 /(1-c)}$

(see Appendix S1). We estimated the parameters $r$ and $c$ by minimizing the sum of squared differences between the log of mean observed growth and the log of growth expected given the mean initial diameter (eqn 2).

The growth scaling parameters ( $r$ and $c$ ) were estimated separately for each site and intercensus interval, and for three different size ranges: all sizes combined, small individuals $(<20-\mathrm{cm}$ diameter) only, and large individuals $\geq 20$-cm diameter) only. In each case, 95\% CI on the parameters were obtained by bootstrapping across $50 \times 50$ m subplots.

\section{Mortality}

Size-specific mortality rates were calculated for the same diameter classes and census intervals used for the growth analyses. In calculating mortality rates within each diameter class, we counted as dead those few individuals that were lost from the census because their new diameters were below the $1 \mathrm{~cm}$ census threshold (due to major stem breaks).

We then estimated the power-function relating mortality rate, $m(D)$, and diameter,

$m(D)=a D^{b}$

that was most consistent with the change in mortality rate among size classes. Because mortality changes continuously as growth occurs, power functions for growth and mortality (eqns 1 and 3) imply that the survival probability during a census interval $t$ of an individual that starts with diameter $D_{0}$ is $\exp (-\mu)$ where

$\mu=\frac{a}{r(1-c+b)}\left[\left(D_{0}^{1-c}+r(1-c) t\right)^{1-c+b /(1-c)}-D_{0}^{1-c+b}\right]$

(see Appendix S1). We estimated the parameters $a$ and $b$ by minimizing the sum of squared differences between the log of the observed mortality rate and the log of the mortality rate expected given mean initial diameter and the fitted growth parameters (eqn 4). As for growth, mortality parameters were estimated separately for each study site and intercensus interval, and for size ranges including all individuals, small individuals and large individuals.

\section{RESULTS}

\section{Size allometry and light availability}

Canopy openness increased almost 100-fold between 1- and 30-m height, and the best power-function fit to this increase had an exponent of 1.64 (Fig. 1a, Table 2). The relationships between stem diameter and tree height, crown area and above-ground bimoass were all approximately power functions (Fig. 1b-d). However, height asymptotes and crown area and biomass both increase less steeply at larger diameters; thus, the exponents of best-fit power functions for large individuals are smaller than those for small individuals (Table 2). Consistent with the findings of Chave et al. (2005) that tree biomass is proportional to height times the square of diameter in tropical moist forests, the exponents relating tree biomass to stem diameter are equal to 2 plus the exponents relating tree height to stem diameter (Table 2).

Metabolic ecology assumptions and predictions were inconsistent with the observed patterns. The strong gradient in light availability with size combined with previous research showing that light is a strongly limiting resource 
Figure 1 Data and fitted power functions on the relationships of (a) canopy openness with height above ground, (b) tree height with stem diameter, and (c) tree crown area with stem diameter, for Barro Colorado Island, Panama; and of (d) tree aboveground biomass with stem diameter in wet tropical forests worldwide (Chave et al. 2005). In (a), different symbols and line types denote data and fits for different years. In $(b-d)$, dashed lines show power-function fits to the full data sets; solid lines show separate fits to small $(<20-\mathrm{cm}$ diameter $)$ and large $(\geq 20-\mathrm{cm}$ diameter $)$ individuals. The fitted parameters are given in Table 2 .
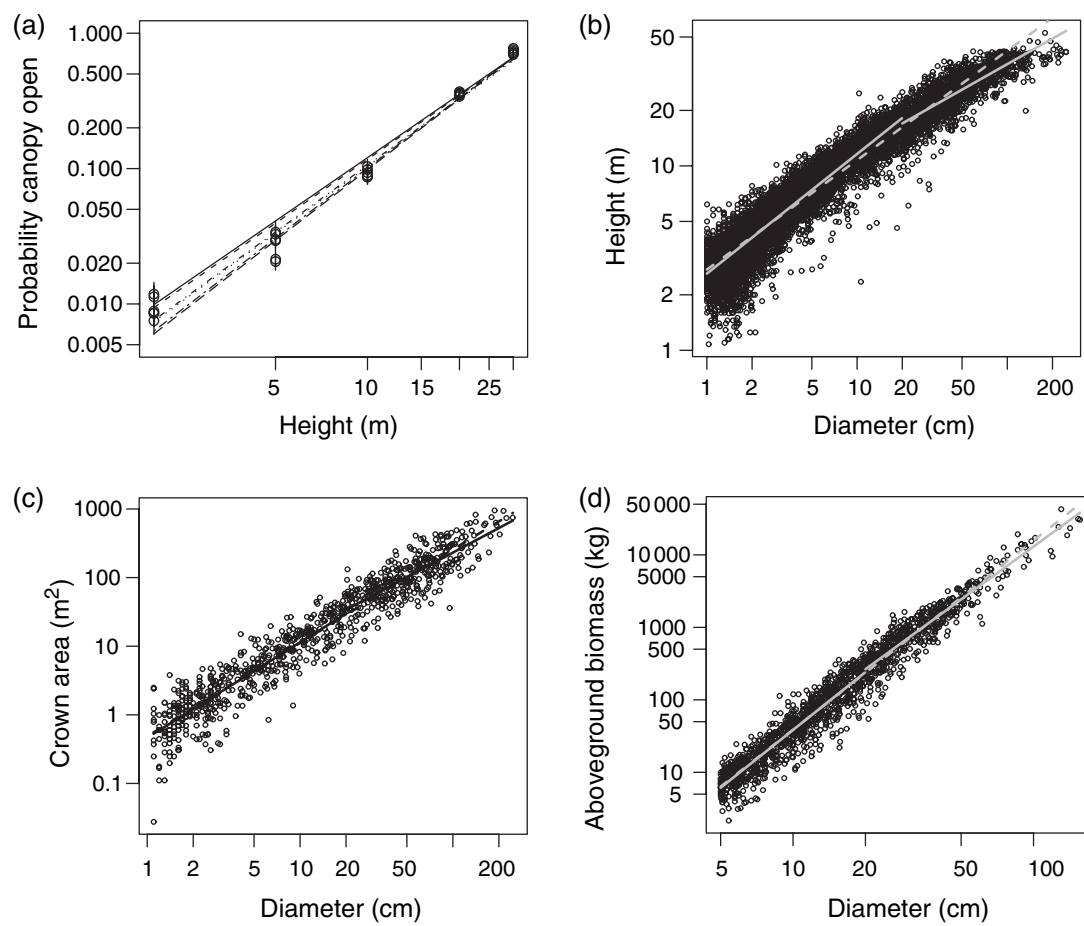

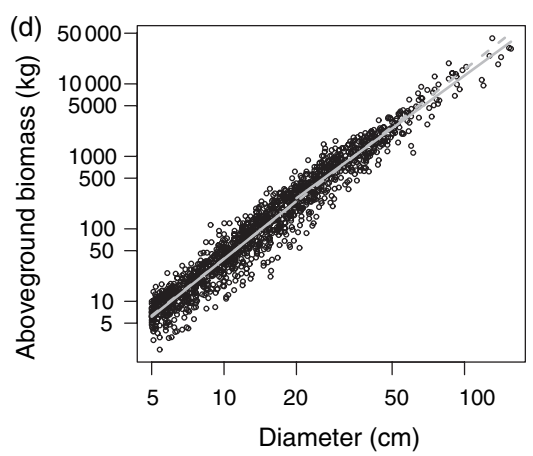

for tropical tree growth (Chazdon \& Pearcy 1986; King 1994; Graham et al. 2003) provides clear evidence against the implied assumption that resource availability is not limiting or is similar across sizes (M2). The observed scaling exponents relating height and biomass to diameter were significantly lower than those predicted by metabolic ecology (M4 and M5). However, the biomass exponent for small individuals alone (2.65) was not significantly different from the predicted $8 / 3$ and the observed height exponent for small individuals (0.649) was close to the predicted 2/3 (although still significantly lower). In contrast, the scaling exponents for large individuals were much lower than predicted, indicating that the metabolic ecology predictions work better for individuals that have not yet reached the canopy than for those within the canopy.

\section{Growth}

Growth rate consistently increased with diameter for small individuals in all closed canopy forests (Fig. 2a-g), but not in the two relatively open canopy sites - Huai Kha Khaeng and Mudumalai (Fig. 2h,i). The rate of increase in growth rate with diameter tended to decrease at larger sizes in closed-canopy sites, as reflected in smaller exponents of the power-function fits for larger individuals - significantly smaller in five of eight sites (Table 3). In the open-canopy sites, this pattern reversed, with larger exponents in larger size classes (significant at Huai Kha Khaeng and in one census at Mudumalai; Table 3). In the closed-canopy sites, power functions were reasonably good fits to growth in small individuals, but performed less well for large individuals. All sites showed slightly S-shaped log-log growth-diameter relationships. Overall, patterns in growth with size at closed-canopy sites were qualitatively similar but significantly different in their slopes and intercepts (Table 3, Table S1).

The scaling of growth was clearly inconsistent with metabolic theory predictions. The observed exponents were significantly different from $1 / 3$, the value predicted by the theory (M9), at nine of 10 sites (Table 3). The only site in which the CI for growth encompassed $1 / 3$ was La Planada, which is exceptional in being a montane site (1845-m elevation). When only small individuals were considered, the fitted growth exponent was significantly different from $1 / 3$ at all census intervals at all 10 sites, while among large individuals the exponent was closer to $1 / 3$, although still significantly different at half the sites despite large CI.

In contrast, growth scaling was consistent with our alternative prediction incorporating the scaling of resource availability among small individuals at the only site where we could test it. The growth exponents for small individuals in Barro Colorado, Panama, in both census intervals (0.78 and 0.67 ) were close to, and not significantly different from, our prediction based on the observed scaling of tree height, crown area and light availability $(0.81$, Table 1$)$.

\section{Mortality}

Mortality was less strongly size-dependent than growth, and changes in mortality with diameter were more variable 


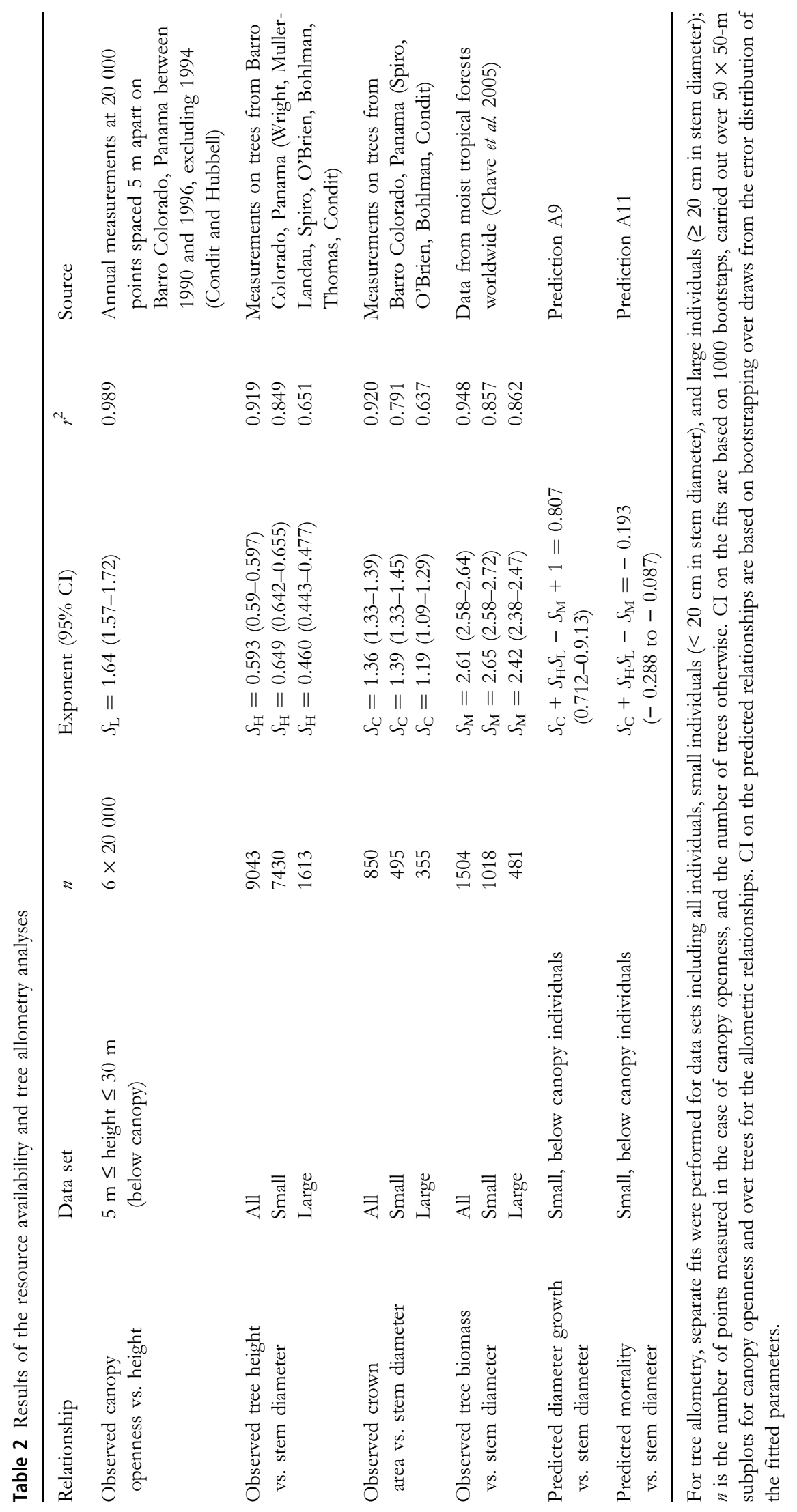



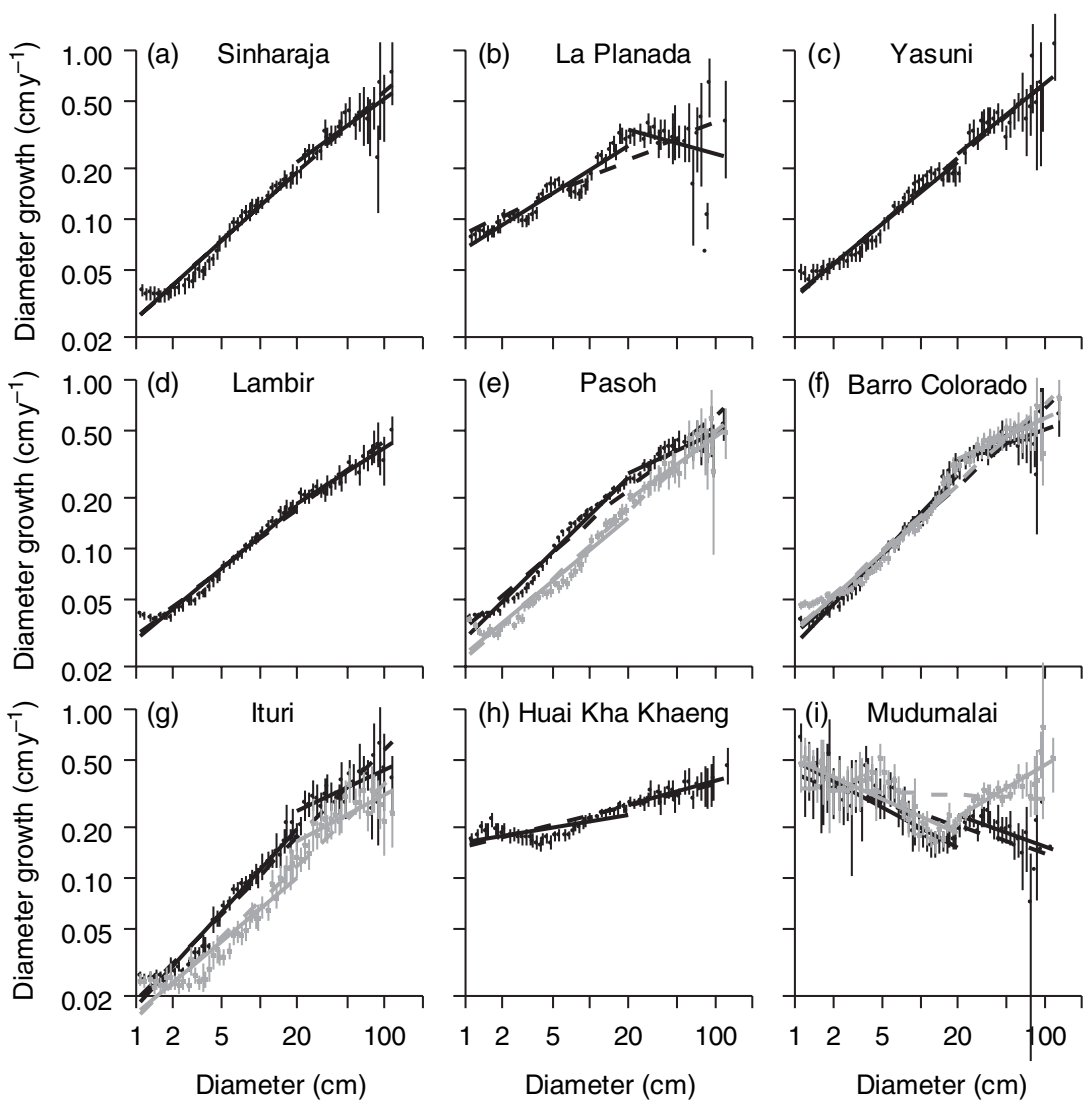

Figure 2 Mean absolute diameter growth rates as a function of diameter for all trees in 10 tropical forests. Vertical lines show $95 \%$ CI based on bootstrapping over $50 \times 50$-m subplots. Thick dashed lines show power-function fits to the full data sets; thick solid lines show separate fits to small ( $<20$-cm diameter) and large $\geq 20$-cm diameter) individuals. When there are two intercensus intervals at the same site, the earlier one is shown in black and the later one in grey. In the case of the Ituri site in the Congo, the results for the Edoro study area are in black and those for the Lenda study area are in grey. Sites are ordered by increasing dryness. The fitted parameters are given in Table 3.

among sites (Fig. 3). Among small individuals, mortality decreased as diameter increased in all 10 tropical forests; however, among large individuals, it variously continued to decrease as diameter increased, ceased to change significantly with diameter or increased with diameter. These changes were reflected in changes in the exponents relating mortality to diameter, which were larger for large individuals than for small individuals at nine of 10 sites, with significant differences at eight sites. Among large individuals, mortality exponents were not significantly different from zero in five of 10 sites, were significantly positive at three sites, and significantly negative at two sites (Table 3). In general, mortality patterns were less well approximated by power functions than were growth patterns, even among small individuals or large individuals alone.

The scaling of mortality rates with diameter was clearly inconsistent with metabolic ecology predictions at all sites, while consistent with our resource scaling alternative where it could be evaluated. Specifically, the exponents relating mortality to diameter for all individuals combined and for small individuals alone were significantly different from the $-2 / 3$ value predicted by metabolic theory (M11): the exponents were significantly smaller at the driest site Mudumalai, and significantly larger at all other sites (Table 3). The values of the mortality exponent for small individuals in Panama in both census intervals $(-0.33$ and -0.26) were much closer to, and not significantly different from, the prediction for this site based on the scaling of resource availability $(-0.19)$.

\section{DISCUSSION}

\section{Assessing metabolic ecology theory for tropical forests}

The predictions of metabolic ecology theory regarding the scaling of height, biomass, diameter growth and mortality with tree diameter were all rejected for tropical forests. Given that our alternative predictions based on the scaling of resource availability were closer to the observed values and were not rejected, we conclude that the implicit 
H. C. Muller-Landau et al.

Table 3 Results of power-function fits of absolute diameter growth rates and mortality rates to tree diameter in 10 tropical forests

\begin{tabular}{|c|c|c|c|c|c|c|c|}
\hline Site & $\begin{array}{l}\text { Census } \\
\text { interval }\end{array}$ & $\begin{array}{l}\text { Data } \\
\text { set }\end{array}$ & $N_{\text {grow }}$ & $N_{\text {mort }}$ & Growth exponent $(c)$ & Mortality exponent $(b)$ & $\begin{array}{l}\text { Difference in } \\
\text { exponents }(c-b)\end{array}$ \\
\hline \multirow{3}{*}{ Sinharaja } & \multirow[t]{3}{*}{$1995-2000$} & All & 170955 & 195627 & $\mathbf{0 . 6 7 9}(0.643 \text { to } 0.706)^{*}$ & $0.125(0.043 \text { to } 0.175)^{*}$ & $0.554(0.48 \text { to } 0.627)^{*}$ \\
\hline & & Small & 164889 & 188555 & $0.687(0.651 \text { to } 0.721)^{*}$ & $\mathbf{- 0 . 1 9 5}(-0.249 \text { to }-0.152)^{*}$ & $0.882(0.8220 \text { to } 0.941)^{*}$ \\
\hline & & Large & 6066 & 7072 & 0.539 (0.347 to 0.658$)^{*}$ & $\mathbf{0 . 7 2 6}(0.367 \text { to } 0.959)^{*}$ & $-0.187(-0.521 \text { to } 0.147)^{*}$ \\
\hline \multirow[t]{3}{*}{ La Planada } & \multirow[t]{3}{*}{$1997-2003$} & All & 76610 & 108751 & 0.344 (0.302 to 0.407$)$ & $-0.400(-0.500 \text { to }-0.358)^{*}$ & $0.744(0.655 \text { to } 0.832)^{*}$ \\
\hline & & Small & 72760 & 104107 & $\mathbf{0 . 4 8 8}(0.462 \text { to } 0.514)^{*}$ & $-\mathbf{0 . 5 5 8}(-0.596 \text { to }-0.522)^{*}$ & $1.045(1 \text { to } 1.091)^{*}$ \\
\hline & & large & 3850 & 4644 & $\mathbf{- 0 . 2 0 5}(-0.452 \text { to } 0.122)^{*}$ & $\mathbf{0 . 3 9 9}(-0.329 \text { to } 0.804)^{*}$ & $-0.603(-1.238 \text { to } 0.032)^{*}$ \\
\hline \multirow[t]{3}{*}{ Yasuni } & \multirow[t]{3}{*}{$1997-2004$} & All & 115827 & 146941 & $\mathbf{0 . 6 4 5}(0.607 \text { to } 0.670)^{*}$ & $-0.024(-0.120 \text { to } 0.018)^{*}$ & $0.669(0.592 \text { to } 0.745)^{*}$ \\
\hline & & Small & 111441 & 141461 & $0.613(0.583 \text { to } 0.644)^{*}$ & $\mathbf{- 0 . 3 3 5}(-0.380 \text { to }-0.289)^{*}$ & 0.949 (0.894 to 1.003$)$ \\
\hline & & large & 4386 & 5480 & $0.618(0.428 \text { to } 0.746)^{*}$ & $\mathbf{0 . 5 3 7}(0.046 \text { to } 0.853)^{*}$ & $0.081(-0.353 \text { to } 0.514)^{*}$ \\
\hline \multirow[t]{3}{*}{ Lambir } & \multirow[t]{3}{*}{ 1992-1997 } & All & 305712 & 335457 & $0.584(0.567 \text { to } 0.600)^{*}$ & $\mathbf{- 0 . 2 1 3}(-0.269 \text { to }-0.161)^{*}$ & $0.797(0.741 \text { to } 0.854)^{*}$ \\
\hline & & Small & 294450 & 323502 & $\mathbf{0 . 6 2 0}(0.596 \text { to } 0.645)^{*}$ & $-0.189(-0.227 \text { to }-0.158)^{*}$ & 0.809 (0.766 to 0.852$)^{*}$ \\
\hline & & Large & 11262 & 11955 & $\mathbf{0 . 4 8 3}(0.395 \text { to } 0.557)^{*}$ & $-0.462(-0.744$ to -0.138$)$ & $0.945(0.631$ to 1.258$)$ \\
\hline \multirow[t]{6}{*}{ Pasoh } & \multirow[t]{3}{*}{ 1990-1995 } & All & 275766 & 315665 & $0.640(0.621 \text { to } 0.657)^{*}$ & $\mathbf{- 0 . 1 0 3}(-0.159 \text { to }-0.063)^{*}$ & $0.743(0.692 \text { to } 0.794)^{*}$ \\
\hline & & Small & 267926 & 306925 & $\mathbf{0 . 7 4 7}(0.733 \text { to } 0.763)^{*}$ & $-0.320(-0.353 \text { to }-0.293)^{*}$ & $1.067(1.034 \text { to } 1.101)^{*}$ \\
\hline & & Large & 7840 & 8740 & $\mathbf{0 . 3 6 0}(0.265$ to 0.438$)$ & $-0.038(-0.333 \text { to } 0.205)^{*}$ & $0.397(0.115 \text { to } 0.68)^{*}$ \\
\hline & \multirow[t]{3}{*}{$1995-2000$} & All & 263845 & 310004 & $\mathbf{0 . 6 7 7}(0.644 \text { to } 0.699)^{*}$ & $-0.079(-0.143 \text { to }-0.047)^{*}$ & $0.756(0.701 \text { to } 0.811)^{*}$ \\
\hline & & Small & 256001 & 300929 & $0.636(0.615 \text { to } 0.658)^{*}$ & $\mathbf{- 0 . 3 0 3}(-0.334 \text { to }-0.277)^{*}$ & $0.94(0.904 \text { to } 0.975)^{*}$ \\
\hline & & Large & 7844 & 9075 & $0.554(0.365 \text { to } 0.664)^{*}$ & $\mathbf{0 . 2 9 5}(-0.023 \text { to } 0.479)^{*}$ & $0.259(-0.033 \text { to } 0.551)^{*}$ \\
\hline \multirow{6}{*}{$\begin{array}{l}\text { Barro } \\
\text { Colorado }\end{array}$} & \multirow[t]{3}{*}{ 1990-1995 } & All & 192091 & 235745 & $0.680(0.652 \text { to } 0.701)^{*}$ & $\mathbf{- 0 . 2 1 6}(-0.280 \text { to }-0.175)^{*}$ & $0.897(0.839 \text { to } 0.954)^{*}$ \\
\hline & & Small & 186080 & 227990 & $\mathbf{0 . 7 7 6}(0.751 \text { to } 0.799)^{*}$ & $-0.329(-0.365 \text { to }-0.297)^{*}$ & $1.105(1.064 \text { to } 1.147)^{*}$ \\
\hline & & Large & 6011 & 7755 & $\mathbf{0 . 2 7 5}(0.128$ to 0.39$)$ & $-0.193(-0.541 \text { to } 0.046)^{*}$ & $0.468(0.146 \text { to } 0.789)^{*}$ \\
\hline & \multirow[t]{3}{*}{$1995-2000$} & All & 182607 & 221136 & 0.674 (0.651 to 0.692$)^{*}$ & $\mathbf{- 0 . 2 1 7}(-0.278 \text { to }-0.177)^{*}$ & 0.891 (0.837 to 0.945$)^{*}$ \\
\hline & & Small & 175866 & 213315 & $\mathbf{0 . 6 7 3}(0.652 \text { to } 0.695)^{*}$ & $-0.264(-0.298 \text { to }-0.231)^{*}$ & $0.937(0.898 \text { to } 0.976)^{*}$ \\
\hline & & Large & 6741 & 7821 & $\mathbf{0 . 3 5 7}(0.23$ to 0.452$)$ & $-0.171(-0.488 \text { to } 0.066)^{*}$ & $0.528(0.229 \text { to } 0.826)^{*}$ \\
\hline \multirow[t]{3}{*}{ Ituri-Edoro } & \multirow[t]{3}{*}{$1995-2000$} & All & 136613 & 152827 & $0.751(0.719 \text { to } 0.771)^{*}$ & $-0.017(-0.096 \text { to } 0.029)^{*}$ & $0.768(0.701 \text { to } 0.836)^{*}$ \\
\hline & & Small & 134302 & 150284 & $\mathbf{0 . 8 1 7}(0.782 \text { to } 0.848)^{*}$ & $\mathbf{- 0 . 1 9 7}(-0.281 \text { to }-0.144)^{*}$ & 1.015 (0.939 to 1.091$)$ \\
\hline & & Large & 2311 & 2543 & $\mathbf{0 . 3 5 1}(0.165$ to 0.478$)$ & $\mathbf{0 . 7 7 0}(0.499 \text { to } 1.224)^{*}$ & $-0.418(-0.813 \text { to }-0.023)^{*}$ \\
\hline \multirow[t]{3}{*}{ Ituri-Lenda } & \multirow[t]{3}{*}{$1995-2000$} & All & 114849 & 127684 & $0.705(0.671 \text { to } 0.727)^{*}$ & $-0.236(-0.328 \text { to }-0.171)^{*}$ & 0.941 (0.857 to 1.025$)$ \\
\hline & & Small & 112029 & 124711 & $\mathbf{0 . 6 2 5}(0.582 \text { to } 0.668)^{*}$ & $\mathbf{- 0 . 3 8}(-0.484 \text { to }-0.316)^{*}$ & $1.005(0.91$ to 1.099$)$ \\
\hline & & Large & 2820 & 2973 & $\mathbf{0 . 4 0 1}(0.247$ to 0.528$)$ & $\mathbf{0 . 2 9 0}(-0.024 \text { to } 0.876)^{*}$ & $0.111(-0.36 \text { to } 0.583)^{*}$ \\
\hline \multirow{3}{*}{$\begin{array}{l}\text { Huai Kha } \\
\text { Khaeng }\end{array}$} & \multirow[t]{3}{*}{ 1993-1999 } & All & 52949 & 75573 & $\mathbf{0 . 2 0 2}(0.179 \text { to } 0.222)^{*}$ & $-0.591(-0.635 \text { to }-0.523)^{*}$ & $0.792(0.732 \text { to } 0.852)^{*}$ \\
\hline & & Small & 45499 & 67021 & $0.135(0.108 \text { to } 0.162)^{*}$ & $\mathbf{- 0 . 9 2 6}(-0.974 \text { to }-0.881)^{*}$ & 1.062 (1.008 to 1.116$)^{*}$ \\
\hline & & Large & 7450 & 8552 & $0.213(0.127 \text { to } 0.295)^{*}$ & $\mathbf{- 0 . 6 6 6}(-0.823$ to -0.242$)$ & 0.879 (0.577 to 1.181$)$ \\
\hline \multirow[t]{6}{*}{ Mudumalai } & \multirow[t]{3}{*}{ 1992-1996 } & All & 13665 & 17479 & $\mathbf{- 0 . 2 5 9}(-0.377 \text { to }-0.194)^{*}$ & $-1.175(-1.319 \text { to }-1.111)^{*}$ & 0.916 (0.777 to 1.054$)$ \\
\hline & & Small & 5443 & 8494 & $-0.485(-0.598 \text { to }-0.367)^{*}$ & $-\mathbf{1 . 0 2 7}(-1.144 \text { to }-0.922)^{*}$ & $0.541(0.381 \text { to } 0.701)^{*}$ \\
\hline & & Large & 8222 & 8985 & $-0.268(-0.842 \text { to } 0.001)^{*}$ & $\mathbf{0 . 0 1 5}(-0.604 \text { to } 0.479)^{*}$ & $-0.283(-0.969 \text { to } 0.403)^{*}$ \\
\hline & \multirow[t]{3}{*}{$1996-2000$} & All & 13556 & 15284 & $-0.032(-0.076 \text { to } 0.004)^{*}$ & $-0.901(-1.064 \text { to }-0.793)^{*}$ & $0.869(0.727$ to 1.01$)$ \\
\hline & & Small & 5094 & 6374 & $\mathbf{- 0 . 4 2 2}(-0.495 \text { to }-0.34)^{*}$ & $\mathbf{- 0 . 8 0 5}(-0.936$ to -0.612$)$ & $0.383(0.204 \text { to } 0.562)^{*}$ \\
\hline & & Large & 8462 & 8910 & $\mathbf{0 . 4 4 2}(0.250$ to 0.572$)$ & $\mathbf{0 . 1 4 4}(-0.577 \text { to } 0.606)^{*}$ & $0.298(-0.315 \text { to } 0.912)^{*}$ \\
\hline
\end{tabular}

Separate fits were performed for data sets including all individuals, small individuals $\left(<20\right.$-cm diameter), and large individuals $\left(\geq 20\right.$-cm diameter). $N_{\text {grow }}$ and $N_{\text {mort }}$ are the numbers of individuals included in the growth and mortality fits respectively. CI (95\%) on the fitted exponents are based on 1000 bootstaps over $50 \times 50$-m subplots.

*Indicates values that are significantly different from the predictions of metabolic ecology theory $(1 / 3$ for the growth exponent, $-2 / 3$ for the mortality exponent, 1 for the difference in exponents). When the exponents for small and large stems are significantly different, those estimates are boldface; when they are not significantly different, the estimate for all stems is in boldface. Plots are ordered in increasing dryness (Table 1).

assumption of metabolic ecology that the scaling of gross photosynthetic rates depends only on the scaling of the potential for resource capture and redistribution (M3) is faulty. Photosynthesis of tropical trees is commonly limited by light availability (Chazdon \& Pearcy 1986; Pearcy et al. 1994; Graham et al. 2003), and competition for light among terrestrial plants is strongly size asymmetric (Weiner 1990). This asymmetry and the resulting changes in light availability with size need to be considered in order to understand the scaling of gross photosynthetic rate with plant size in closed canopy forests. The scaling predicted by metabolic ecology may yet prove a good approximation for individual trees grown in the absence of competition, and in systems in which high mortality severely reduces competition. However, it cannot begin to explain variation in growth rates found over the eight orders of magnitude variation in individual biomass between understory saplings and canopy trees within a forest. 
Figure 3 Mean mortality rates as a function of diameter for all trees in 10 tropical forests. Vertical lines show 95\% CI based on bootstrapping over $50 \times 50-\mathrm{m}$ subplots. Thick dashed lines show power-function fits to the full data sets; thick solid lines show separate fits to small $(<20$-cm diameter) and large $\geq 20-\mathrm{cm}$ diameter) individuals. When there are two intercensus intervals at the same site, the earlier one is shown in black and the later one in grey. In the case of the Ituri site in the Congo, the results for the Edoro study area are in black and those for the Lenda study area are in grey. Sites are ordered by increasing dryness. The fitted parameters are given in Table 3.
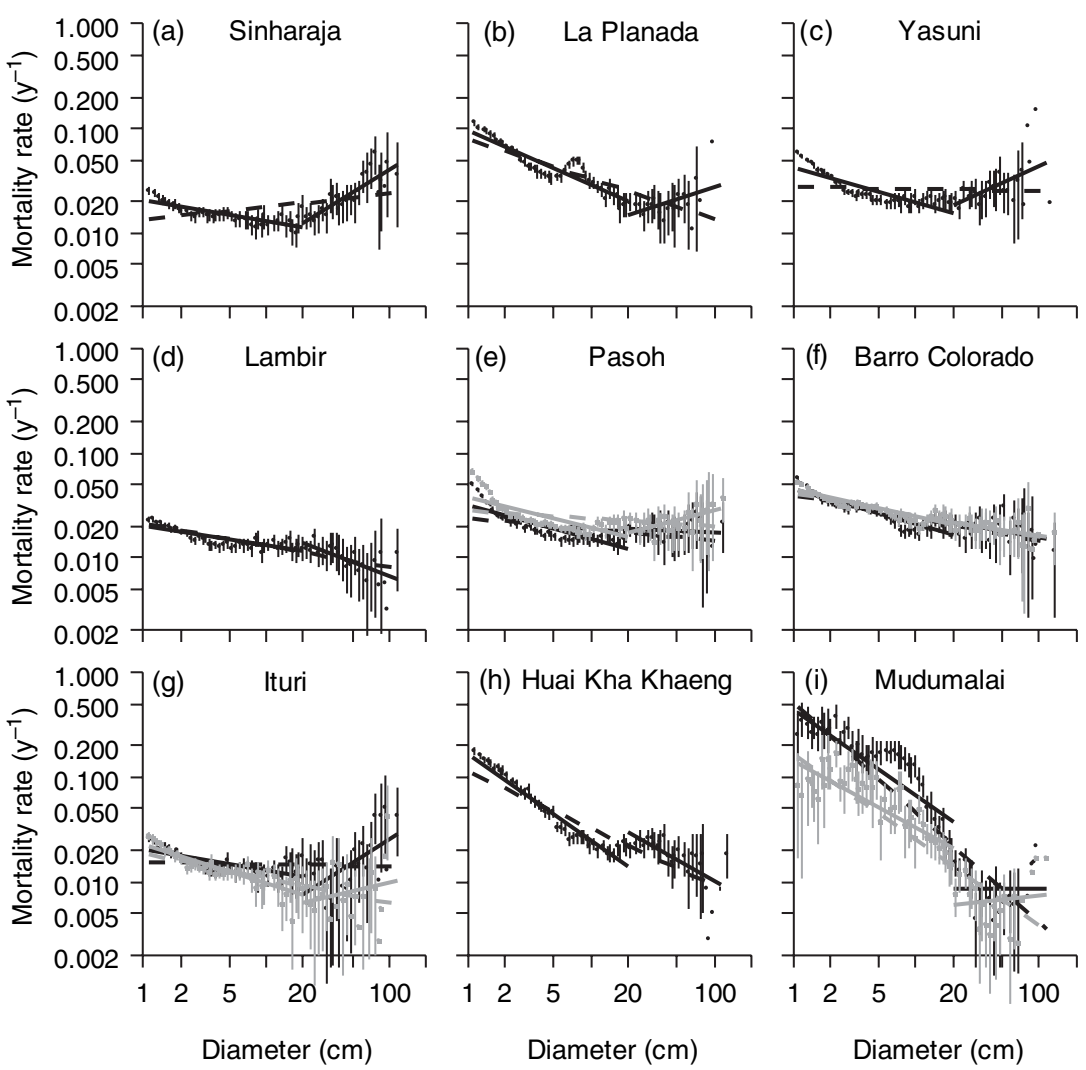

Taken together, the results suggest that one or both of the assumptions that tree growth and mortality rates scale with gross and mass-specific photosynthetic rates, respectively (M9 and M11), must also be rejected for the forest as a whole, although they may be appropriate for understory individuals. No matter what the scaling of photosynthetic rates with size, this combination of assumptions means that the difference between the exponents of growth and mortality $(c-b)$ should be exactly one (M12). For all trees combined and especially for large individuals alone, the difference between the growth and mortality exponents was significantly $>1$ in all but one closed-canopy forest (IturiLenda, Table 3). Thus, there does not exist any scaling of photosynthesis with size that can reconcile these patterns with the assumptions that tree growth and mortality rates scale with gross and mass-specific photosynthetic rates respectively. We hypothesize that these deviations result mainly from strong size dependence of some mortality threats independent of resource availability and photosynthetic rates (Coomes et al. 2003). Size-dependent changes in allocation to reproduction may also contribute to this pattern (Thomas 1996; Wright et al. 2005). Among small individuals in closed-canopy forests, in contrast, the difference between growth and mortality exponents is generally close to 1 , although still significantly different from one for most sites (Table 3). This suggests that for trees in the understory, growth and mortality may scale with photosynthesis approximately as hypothesized in metabolic ecology theory; this idea is further supported by the success of our alternative predictions for below-canopy individuals that incorporate these assumptions regarding the relationship of growth and mortality to photosynthesis, while changing assumptions regarding how photosynthesis scales with size.

Both basic metabolic ecology theory and the variation upon it that we present here treat all individuals within the forest as identical in terms of demographic parameters and underlying physiological processes. These theories thus ignore ontogenetic and interspecific variation, and essentially average over it in making their predictions. Explicit consideration of known size-dependent changes in maintenance costs could lead to better predictions for biomass growth (Kooijman 2000). Several authors have already begun to consider how ontogenetic changes in maintenance costs might be incorporated into metabolic ecology theory (West et al. 2001); what we need now is a synthesis that considers interspecific as well as intraspecific variation in maintenance with size. There is abundant evidence that tropical tree species show large differences in stem allometry (O’Brien et al. 1995), photosynthesis (Kitajima 1994) and wood density (Muller-Landau 2004), as well as in ontogenetic variation in physiology and allometry (Poorter et al. 
2003; Bohlman \& O'Brien 2006). Thus, it is not surprising that there is considerable interspecific variation in demographic rates (Condit et al. 1993, 1995). It is likely that both interspecific differences and ontogenetic changes within a given species are important influences on the observed sizedependent patterns in growth and mortality for the forest as a whole, and that a complete understanding of patterns within and across sites will eventually require explicit consideration of such variability.

\section{Significance and future directions}

The results presented here indicate that, despite qualitative similarities in some patterns, there are no universal scaling relationships of photosynthetic rates, growth rates, or mortality rates with size among trees in forests. Instead, there are significant quantitative differences in the allometric scaling of demographic rates among forests, differences that our work suggests are related proximally to among-site variation in tree allometries and the scaling of light availability. Of course, the scaling of light availability within forests itself depends on the tree size distribution (Denslow \& Guzman 2000; Montgomery \& Chazdon 2001), which can be derived from the growth and mortality functions in old-growth forests (Kohyama et al. 2003). Likewise, the height and crown allometries of trees reflect plastic responses to resource availability as well as ecological sorting and natural selection of species for success within the local resource competition environment (Iwasa et al. 1985; King \& Maindonald 1999; Poorter et al. 2003; Kitajima et al. 2005). Ultimately, we would like to not only explain size distributions in terms of growth and mortality, and growth and mortality in terms of allometries and light, but also all of these patterns simultaneously from more fundamental physiological and physical characteristics of trees and sites.

We hypothesize that the key factor for understanding variation in demographic rates among forests is the degree to which large individuals can monopolize resources versus the degree to which their abundance and resource monopolization are limited by other factors such as lethal disturbances (Coomes et al. 2003) or relatively more symmetric resource competition (Stoll et al. 2002). Amongsite variation in growth and mortality is greatest between closed and open canopy forests. In open canopy forests, the abundance of large trees is below its theoretical maximum in the two forests here because of the effects of fire and elephants on the recruitment and mortality rates of large trees (Sukumar et al. 2005). Where the densities of large trees are limited and canopies are consequently more open, competition for resources is likely to be relatively more symmetric as small individuals have more access to resources. Major disturbances, such as fires and cyclones, that are important causes of large tree mortality and thus of canopy openings in many forests occur over large areas at long time intervals. Thus, it will take many years to accumulate enough data to understand the frequencies of such disturbances and accurately estimate long-term average mortality and growth rates as a function of size.

A mechanistic explanation for size-dependent patterns of tree growth and mortality is not only a fundamental challenge in forest ecology, but also a problem of considerable applied significance. Given the large role of tropical forests in the global carbon cycle, it is important to understand how increases or decreases in tree photosynthetic rates because of carbon fertilization, nitrogen deposition, increased temperature or other global forcings might ultimately affect forest dynamics, and thereby net carbon fluxes (Cramer et al. 2004; Wright 2005). A better mechanistic understanding of the processes governing tree growth and mortality rates and their changes with tree size will shed light not only on geographical variation in these patterns today, but on how future forests are likely to change.

\section{ACKNOWLEDGEMENTS}

We thank Joe Wright, Steve Pacala, Bert Leigh and three anonymous referees for helpful comments on the manuscript. We gratefully acknowledge the contributions of the many dedicated people and generous funders that have made possible the forest dynamics plot data sets upon which this research is based. We especially thank the US National Science Foundation for funding the workshop at which this study was initiated (DEB-9806828). HCM thanks the University of Minnesota and the National Center for Ecological Analysis and Synthesis (a centre funded by NSF and the state of California) for support.

\section{REFERENCES}

Baker, T.R., Swaine, M.D. \& Burslem, D. (2003). Variation in tropical forest growth rates: combined effects of functional group composition and resource availability. Perspect. Plant Ecol. Evol. Syst., 6, 21-36.

Bohlman, S.A. \& O’Brien, S.T. (2006). Allometry, adult stature and regeneration requirements of 65 tree species on Barro Colorado Island, Panama. J. Trop. Ecol, 22, 123-136.

Brown, J.H., Gillooly, J.F., Allen, A.P., Savage, V.M. \& West, G.B. (2004). Toward a metabolic theory of ecology. Ecology, 85, 17711789.

Chave, J., Andalo, C., Brown, S., Cairns, M.A., Chambers, J.Q., Eamus, D. et al. (2005). Tree allometry and improved estimation of carbon stocks and balance in tropical forests. Oecologia, 145, 87-99.

Chazdon, R.L. \& Pearcy, R.W. (1986). Photosynthetic responses to light variation in rain-forest species. 2. Carbon gain and photosynthetic efficiency during lightflecks. Oecologia, 69, 524 531. 
Clark, D.A., Brown, S., Kicklighter, D.W., Chambers, J.Q., Thomlinson, J.R., Ni, J. et al. (2001). Net primary production in tropical forests: an evaluation and synthesis of existing field data. Ecol. Appl., 11, 371-384.

Condit, R. (1998) Tropical Forest Census Plots. Springer-Verlag, Berlin and R. G. Landes Company, Georgetown, TX, USA.

Condit, R., Hubbell, S.P. \& Foster, R.B. (1993). Identifying fastgrowing native trees from the Neotropics using data from a large, permanent census plot. For. Ecol. Manag., 62, 123-143.

Condit, R., Hubbell, S.P. \& Foster, R.B. (1995). Mortality rates of 205 Neotropical tree and shrub species and the impact of a severe drought. Ecol. Monogr., 65, 419-439.

Coomes, D.A., Duncan, R.P., Allen, R.B. \& Truscott, J. (2003). Disturbances prevent stem size-density distributions in natural forests from following scaling relationships. Ecol. Lett., 6, 980-989.

Cramer, W., Bondeau, A., Schaphoff, S., Lucht, W., Smith, B. \& Sitch, S. (2004). Tropical forests and the global carbon cycle: impacts of atmospheric carbon dioxide, climate change and rate of deforestation. Philos. Trans. R. Soc. Lond. Ser. B, Biol. Sci., 359, 331-343.

Denslow, J.S. \& Guzman, S. (2000). Variation in stand structure, light and seedling abundance across a tropical moist forest chronosequence, Panama. J. Vegetat. Sci., 11, 201-212.

Dodds, P.S., Rothman, D.H. \& Weitz, J.S. (2001). Re-examination of the "3/4-law" of metabolism. J. Theor. Biol., 209, 9-27.

Enquist, B.J. \& Niklas, K.J. (2002). Global allocation rules for patterns of biomass partitioning in seed plants. Science, 295, 1517-1520.

Enquist, B.J., Brown, J.H. \& West, G.B. (1998). Allometric scaling of plant energetics and population density. Nature, 395, 163-165.

Enquist, B.J., West, G.B., Charnov, E.L. \& Brown, J.H. (1999). Allometric scaling of production and life-history variation in vascular plants. Nature, 401, 907-911.

Ernest, S.K.M., Enquist, B.J., Brown, J.H., Charnov, E.L., Gillooly, J.F., Savage, V.M. et al. (2003). Thermodynamic and metabolic effects on the scaling of production and population energy use. Ecol. Lett., 6, 990-995.

Graham, E.A., Mulkey, S.S., Kitajima, K., Phillips, N.G. \& Wright, S.J. (2003). Cloud cover limits net $\mathrm{CO}_{2}$ uptake and growth of a rainforest tree during tropical rainy seasons. Proc. Natl Acad. Sci. USA, 100, 572-576.

Hubbell, S.P., Foster, R.B., O’Brien, S.T., Harms, K.E., Condit, R., Wechsler, B. et al. (1999). Light-gap disturbances, recruitment limitation, and tree diversity in a neotropical forest. Science, 283, 554-557.

Ickes, K., Paciorek, C.J. \& Thomas, S.C. (2005). Impacts of nest construction by native pigs (Sus scrofa) on lowland Malaysian rain forest saplings. Ecology, 86, 1540-1547.

Iwasa, Y., Cohen, D. \& León, J.A. (1985). Tree height and crown shape, as results of competitive games. J. Theor. Biol., 112, 279-297.

King, D.A. (1994). Influence of light level on the growth and morphology of saplings in a Panamania forest. Am. J. Bot., 81, 948-957.

King, D.A. \& Maindonald, J.H. (1999). Tree architecture in relation to leaf dimensions and tree stature in temperate and tropical rain forests. J. Ecol., 87, 1012-1024.

Kirschbaum, M.U.F., King, D.A., Comins, H.N., McMurtrie, R.E., Medlyn, B.E., Pongracic, S. et al. (1994). Modelling forest response to increasing $\mathrm{CO}_{2}$ concentration under nutrient-limited conditions. Plant Cell Environ., 17, 1081-1099.
Kitajima, K. (1994). Relative importance of photosynthetic traits and allocation patterns as correlates of seedling shade tolerance of 13 tropical trees. Oecologia, 98, 419-428.

Kitajima, K., Mulkey, S.S. \& Wright, S.J. (2005). Variation in crown light utilization characteristics among tropical canopy trees. Ann. Bot., 95, 535-547.

Kohyama, T., Suzuki, M., Partomihardjo, T., Yamada, T. \& Kubo, T. (2003). Tree species differentiation in growth, recruitment and allometry in relation to maximum height in a Bornean mixed dipterocarp forest. J. Ecol., 91, 797-806.

Kooijman, S.A.L.M. (2000) Dynamic Energy and Mass Budgets in Biological Systems. Cambridge University Press, Cambridge.

Kozlowski, J. \& Konarzewski, M. (2004). Is West, Brown and Enquist's model of allometric scaling mathematically correct and biologically relevant? Funct. Ecol., 18, 283-289.

Li, H.-T., Han, X.-G. \& Wu, J.-G. (2005). Lack of evidence for 3/4 scaling of metabolism in terrestrial plants. J. Integr. Plant Biol., 47, 1173.

Losos, E.C. \& Leigh, E.G. (2004) Forest Diversity and Dynamism: Findings From a Network of Large-Scale Tropical Forest Plots. University of Chicago Press, Chicago, IL.

Meinzer, F.C., Bond, B.J., Warren, J.M. \& Woodruff, D.R. (2005). Does water transport scale universally with tree size? Funct. Ecol., 19, 558-565.

Montgomery, R.A. \& Chazdon, R.L. (2001). Forest structure, canopy architecture, and light transmittance in tropical wet forests. Ecology, 82, 2707-2718.

Muller-Landau, H.C. (2004). Interspecific and inter-site variation in wood specific gravity of tropical trees. Biotropica, 36, 20-32.

Niklas, K.J. \& Enquist, B.J. (2001). Invariant scaling relationships for interspecific plant biomass production rates and body size. Proc. Natl Acad. Sci. USA, 98, 2922-2927.

O’Brien, S.T., Hubbell, S.P., Spiro, P., Condit, R. \& Foster, R.B. (1995). Diameter, height, crown, and age relationships in eight Neotropical tree species. Ecology, 76, 1926-1939.

Pearcy, R.W., Chazdon, R.L., Gross, L.J. \& Mott, K.A. (1994). Photosynthetic utilization of sunflecks: a temporally patchy resource on a time scale of seconds to minutes. In: Exploitation of Environmental Heterogeneity by Plants: Ecophysiological Processes Aboveand Belowground (eds Caldwell, M.M. \& Pearcy, R.W.). pp. 175208. Academic Press, San Diego, CA.

Phillips, O.L., Malhi, Y., Higuchi, N., Laurance, W.F., Nunez, P.V., Vasquez, R.M. et al. (1998). Changes in the carbon balance of tropical forests: evidence from long-term plots. Science, 282, 439-442.

Phillips, O.L., Baker, T.R., Arroyo, L., Higuchi, N., Killeen, T.J., Laurance, W.F. et al. (2004). Pattern and process in Amazon tree turnover, 1976-2001. Philos. Trans. R. Soc. Lond. Ser. B, Biol. Sci., 359, 381-407.

Poorter, L., Bongers, F., Sterck, F.J. \& Woll, H. (2003). Architecture of 53 rain forest tree species differing in adult stature and shade tolerance. Ecology, 84, 602-608.

Sands, P.J. (1996). Modelling canopy production. III. Canopy light-utilisation efficiency and its sensitivity to physiological and environmental variables. Aust. J. Plant Physiol., 23, 103114.

Stoll, P., Weiner, J., Muller-Landau, H., Müller, E. \& Hara, T. (2002). Size symmetry of competition alters biomass-density relations. Proc. R. Soc. Biol. Sci. Ser. B, 269, 2191-2195. 
Sukumar, R., Suresh, H.S., Dattaraja, H.S., Srinidhi, S. \& Nath, C. (2005). The dynamics of a tropical dry forest in India: climate, fire, elephants and the evolution of life-history strategies. In: Biotic Interactions in the Tropics: Their Role in the Maintenance of Species Diversity (eds Burslem, D., Pinard, M. \& Hartley, S.). pp. 510 529. Cambridge University Press, Cambridge.

Thomas, S.C. (1996). Relative size at onset of maturity in rain forest trees: a comparative analysis of 37 Malaysian species. Oikos, 76, 145-154.

Tilman, D., HilleRisLambers, J., Harpole, S., Dybzinski, R., Fargione, J., Clark, C. et al. (2004). Does metabolic theory apply to community ecology? It's a matter of scale. Ecology, 85, 1797-1799.

Waring, R.H. \& Running, S.W. (1998) Forest Ecosystems: Analysis at Multiple Scales, 2nd edn. Academic Press, San Diego, CA.

Weiner, J. (1990). Asymmetric competition in plant populations. Trends Ecol. Evol., 5, 360-364.

West, G.B., Brown, J.H. \& Enquist, B.J. (1997). A general model for the origin of allometric scaling laws in biology. Science, 276, 122-126.

West, G.B., Brown, J.H. \& Enquist, B.J. (1999). A general model for the structure and allometry of plant vascular systems. Nature, 400, 664-667.

West, G.B., Brown, J.H. \& Enquist, B.J. (2001). A general model for ontogenetic growth. Nature, 413, 628-631.

Wright, S.J. (2005). Tropical forests in a changing environment. Trends Ecol. Evol., 20, 553-562.
Wright, S.J., Jaramillo, M.A., Pavon, J., Condit, R., Hubbell, S.P. \& Foster, R.B. (2005). Reproductive size thresholds in tropical trees: variation among individuals, species and forests. J. Trop. Ecol., 21, 307-315.

Zimmerman, J.K., Everham, E.M. III, Waide, R.B., Lodge, D.J., Taylor, C.M. \& Brokaw, N.V.L. (1994). Responses of tree species to hurricane winds in subtropical wet forest in Puerto Rico: implications for tropical tree life histories. J. Ecol., 82, 911-922.

\section{SUPPLEMENTARY MATERIAL}

The following material is available online at http:// www.Blackwel-Synergy.com:

Appendix S1 Details of the growth and mortality fits. Table S1 Intercepts of the growth and mortality fits.

Editor, Michael Hochberg

Manuscript received 18 November 2005

First decision made 23 December 2005

Manuscript accepted 23 January 2006 